\title{
Effect of Cooling and Isothermal Holding on the Amount of Martensite/Austenite (M/A) Constituents, Microstructure and Mechanical Properties of Microalloyed Pipeline Steel
}

\author{
Alexander Kabanov ${ }^{1, a^{*}}$, Grzegorz Korpala ${ }^{1, b}$, Rudolf Kawalla ${ }^{1 \mathrm{c}}$ \\ and Sergey lonov ${ }^{2, d}$
}

\author{
${ }^{1}$ Technische Universität Bergakademie Freiberg, Institute of Metal Forming, Freiberg, Germany \\ ${ }^{2}$ The National University of Science and Technology MISiS, Russia \\ aalexander.kabanov@student.tu-freiberg.de, bgrzegorz.korpala@imf.tu-freiberg.de, \\ crudolf.kawalla@imf.tu-freiberg.de, ${ }^{d}$ ionov@pdss.misis.ru
}

Keywords: pipeline steel; heavy plate; thermo-mechanical treatment; bainite with retained austenite; martensite-austenite phase (MA phase)

\begin{abstract}
Constant increase of energy consumption in modern industry requires construction of heavily loaded pipelines with high throughput capacity. Therefore, high-strength steels should be used for the cost reasons. Additionally, the pipelines are also often used in the areas with cold climate and high seismicity. Therefore, strength and plasticity reduction is unacceptable. Bainitic steels with retained austenite (RA) or martensite/austenite (M/A) constituents meet these requirements. The purpose of this investigation is to determine thermo-mechanical treatment parameters with further accelerated cooling and additional isothermal holding for M/A-phase and mechanical properties formation. Experimental modeling of the production process was carried out using Gleeble HDS-V40 thermo-mechanical simulator. All investigations were realized with two high-strength micro-alloyed steels with different molybdenum and carbon content. Results showed that decrease of temperature and duration of isothermal holding as well as addition of molybdenum promote bainitic microstructure nucleation and reduce grain size and $\mathrm{M} / \mathrm{A}$-constituents. All these factors lead to a slight improvement in mechanical properties.
\end{abstract}

\section{Introduction}

Constant increase of energy consumption in the modern industry requires larger oil and gas volumes high pressure pumping over large distances. Pipeline capacities maximization calls for high-strength steels application. Steel strength improvement is achieved mainly by replacing ferritebased microstructures with bainite-based microstructures [1]. However, pipelines are also often built in the areas with cold climate and high seismicity. Therefore strength and plasticity reduction is unacceptable $[2,3]$. Dual-phase microstructure, consisting of hard and soft phases, leads to higher deformability. Recently, steels with microstructure consisting of bainite and martensite/austenite (M/A) constituents have been developed as a result of online heat treatment process with subsequent steel plate heating by induction-heating device after accelerated cooling [2, 4]. Such type of steels can also be obtained by isothermal holding in the bainite transformation temperature range after accelerated cooling [5, 6]. Each of these technologies is based on the same principle: acceleration and increase of carbon diffusion into austenite. This process allows stabilizing of austenite, which turns into a phase consisting of residual austenite and martensite (MA phase). MA phase quantity, size and distribution depend mainly on production technological parameters and steel chemical composition. The disadvantage of these technologies consists in inability of most plants to apply it due to necessary equipment unavailability. Therefore, technological processes, enabling avoiding costly re-equipment, represent high scientific and production value. The goal of the present study was to investigate the effect of different options of thermomechanical processing with various combinations of accelerated cooling and isothermal holding, as well as the content of molybdenum and carbon on microstructure formation, MA phase amount, and mechanical properties of two microalloyed pipeline steels. 


\section{Experimental Materials and Methods}

Experimental investigations were carried out on two pipeline steels microalloyed with niobium, titanium and vanadium. The first steel had a higher carbon content, and the second one was additionally alloyed with molybdenum. The chemical compositions of both steels are shown in Table 1.

Table 1. Chemical compositions of the steels used in this study, wt- $\%$

\begin{tabular}{|c|c|c|c|c|c|c|c|}
\hline Steel & $\mathrm{C}$ & $\mathrm{Mn}$ & $\mathrm{Si}$ & $\mathrm{Ni}$ & $\mathrm{Cu}$ & $\mathrm{Mo}$ & {$[\mathrm{Nb}+\mathrm{Ti}+\mathrm{V}]$} \\
\hline $\mathrm{S} 1$ & 0.1 & 1.8 & 0.25 & 0.2 & 0.2 & 0 & 0.14 \\
\hline $\mathrm{S} 2$ & 0.07 & 1.9 & 0.23 & 0.3 & 0.2 & 0.14 & 0.13 \\
\hline
\end{tabular}

In order to simulate thermo-mechanical rolling with various combinations of cooling and reheating, the plane strain compression tests were conducted using Gleeble HDS-V40 thermomechanical simulator. $10 \mathrm{~mm} \times 50 \mathrm{~mm} \times 150 \mathrm{~mm}$ plate samples were used in this investigation. At first, the samples were austenitized at $1250^{\circ} \mathrm{C}$ for approximately $5 \mathrm{~min}$ and afterward deformed in three steps. The cooling rate between the deformation steps was $2 \mathrm{~K} / \mathrm{s} .2$ second interval was used between the initial two steps. In order to refine the microstructure, the last deformation was carried out in austenite non-recrystallization temperature range $\left(900^{\circ} \mathrm{C}\right)$. After that, the samples were cooled down with a different cooling and isothermal holding combination $(\mathrm{C})$ presented in Fig. 1:

$\mathrm{C} 1$. accelerated cooling with two different rates to the different cooling stop temperatures.

C2. accelerated cooling to different temperatures in the bainite transformation range with the following isothermal holding durations options;

Accelerated cooling and isothermal holding parameters were determined based on DCCT diagrams data obtained in [3]. Therefore, the accelerated cooling rate was chosen to be $30 \mathrm{~K} / \mathrm{s}$, which may be applied to about $10 \mathrm{~mm}$ thick plate. Moreover, to determine accelerated cooling rate effect on microstructure and MA phase formation, $10 \mathrm{~K} / \mathrm{s}$ rate was applied in the combination with C1.

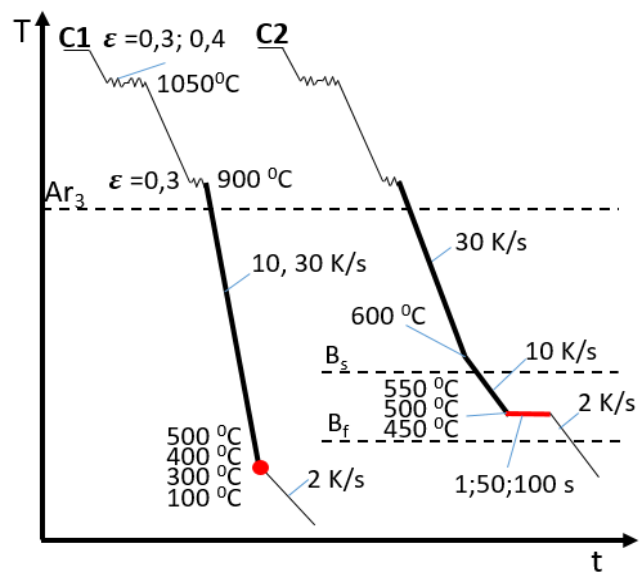

Fig. 1. Schematic illustration of accelerated cooling and heat treatment combinations applied in this study, where $\mathrm{Ar}_{3}$ - austenite transformation start temperature at the cooling; $\varepsilon$ - the degree of deformation; $\mathrm{Bs}$ and $\mathrm{Bf}$ - respective temperatures of bainite transformation start and end

After each experiment, the samples were cooled down at the rate of $2 \mathrm{~K} / \mathrm{s}$ to room temperature and cut into samples for the tensile tests and microstructural analysis. It should be mentioned that the samples for the tensile test had geometry and dimensions, which is not specified in the standards. However, the present results allow evaluating the mechanical properties modification depending on the experiment conditions in the framework of this study. In addition, the metallographic samples were made and etched by two methods. Nital was applied for ferrite and bainite quantitative and general microstructural analysis. For MA phase identification, the color etching "LePera" was chosen. After that, the etched metallographic samples were analyzed using light microscopy. In addition, the pictures after the LePera etching were processed in a photo editor using "thresholding" function to create binary black and white images. That allows achieving the optimal contrast of images. It also allows images processing in "JMicroVision" program for MA 
phase particles measuring and quantifying. Moreover, scanning electron microscopy was carried out on some samples for additional control of MA phase.

\section{Results and Discussion}

Influence of the finish temperature and rate of the accelerated cooling on the microstructure and mechanical properties. The rate of accelerated cooling has a huge impact on the microstructure formation, which was shown in $[3,5,7,8]$. Thus, with the decrease of the cooling rate the amount of ferrite in the microstructure as well as the average grain size increase, (Fig. 3a, b). For both steels, the tendency of the MA phase amount decreasing with the slower accelerated cooling is also noticeable. This could be explained by the fact that slow cooling is more favorable for diffusion and leads to the formation of carbide and pearlite. As a result, austenite is not sufficiently stabilized. This effect is clearly seen in the first steel. In the second steel, the effect is less noticeable, due to additional alloying with molybdenum, which slows down carbon diffusion and ferrite transformation. This fact was also described in [9]. As a result, the second steel had a smaller content of ferrite and carbides, as well as a smaller average grain size under all cooling conditions. Moreover, with the increase of accelerated cooling rate, the carbon concentration increases at the grain boundaries, because the carbon does not have enough time to diffuse into the grain [10]. As a result, MA phase has an elongated shape and is located at grain boundaries (Fig. 4). By applying a lower cooling rate, MA phase acquires a more equiaxed shape. Changes in microstructure did not result in a noticeable change of mechanical properties of both steels (Fig. 3c, d). This can be explained by the fact that the bainite obtained in these steels is mostly granular, which is quite similar to ferrite microstructure in morphology. For this reason this type of bainite consists of irregular ferrite with second phases distributed between the irregular ferrite grains [11]. Additionally, with bainite content increase, the amount of carbides decreases due to their redistribution from the ferrite matrix to the bainitic structure.

At high accelerated cooling finish temperature in the bainitic transformation range, the carbon diffusion continues from formed bainite/ferrite to the untransformed austenite. This process stabilizes austenite, which subsequently transforms into the phase consisting of residual austenite and martensite (MA phase). However, when high accelerated cooling finish temperature is applied, carbides and perlite formation can block this process due to carbon concentration decrease in the untransformed austenite. Thus, with the accelerated cooling finish temperature rise, the amount of ferrite increases (Fig. 3a, b), and MA phase particles coarsening occurs (Fig. 2, 4). However, this does not affect the amount of MA phase in the microstructure. It should be also noted that in the first steel at $30 \mathrm{~K} / \mathrm{s}$ cooling rate with accelerated cooling finish temperature rise to $500{ }^{\circ} \mathrm{C}$, MA phase amount drop occurs due to the formation of carbides in the microstructure. As result, mechanical properties deterioration is observed. This effect was not detected in the second steel because of the increased molybdenum content. In other respects, the tendency of slight increase of the elongation and decrease of the strength properties with the increase of accelerated cooling finish temperature is observed for the both steels (Fig. 3c, d).
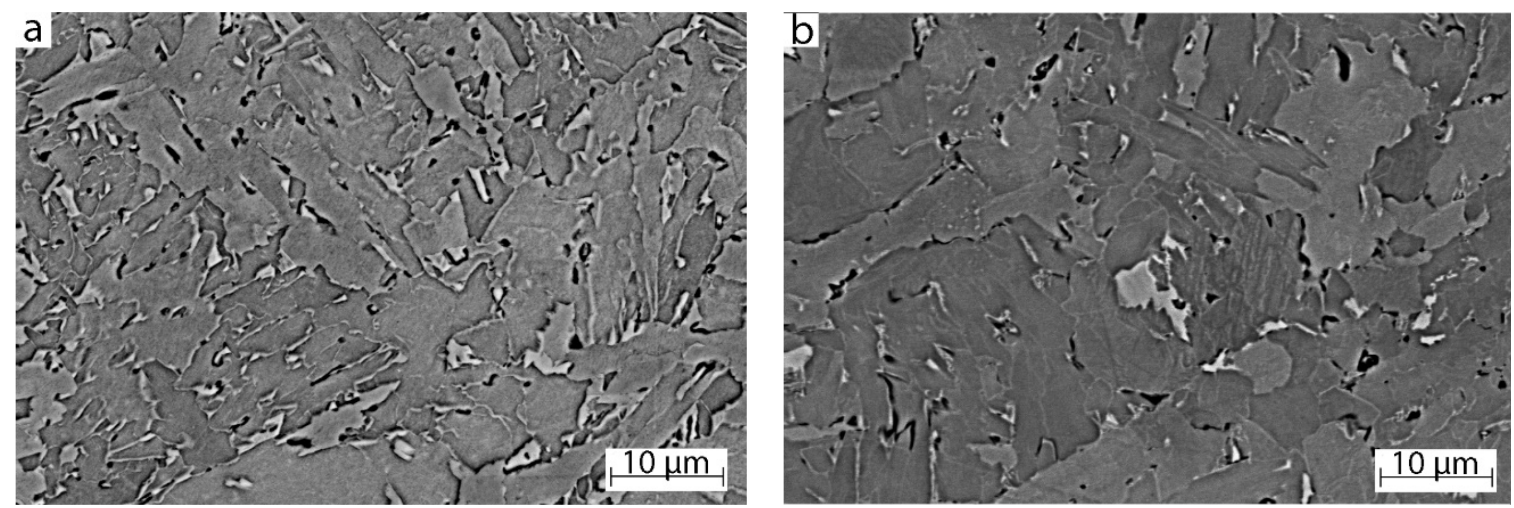

Fig. 2. SEM images of the steel 2 at the cooling rate of $30 \mathrm{~K} / \mathrm{s}$ and different cooling finish temperatures: a) $300^{\circ} \mathrm{C}$; b) $500^{\circ} \mathrm{C}$ 

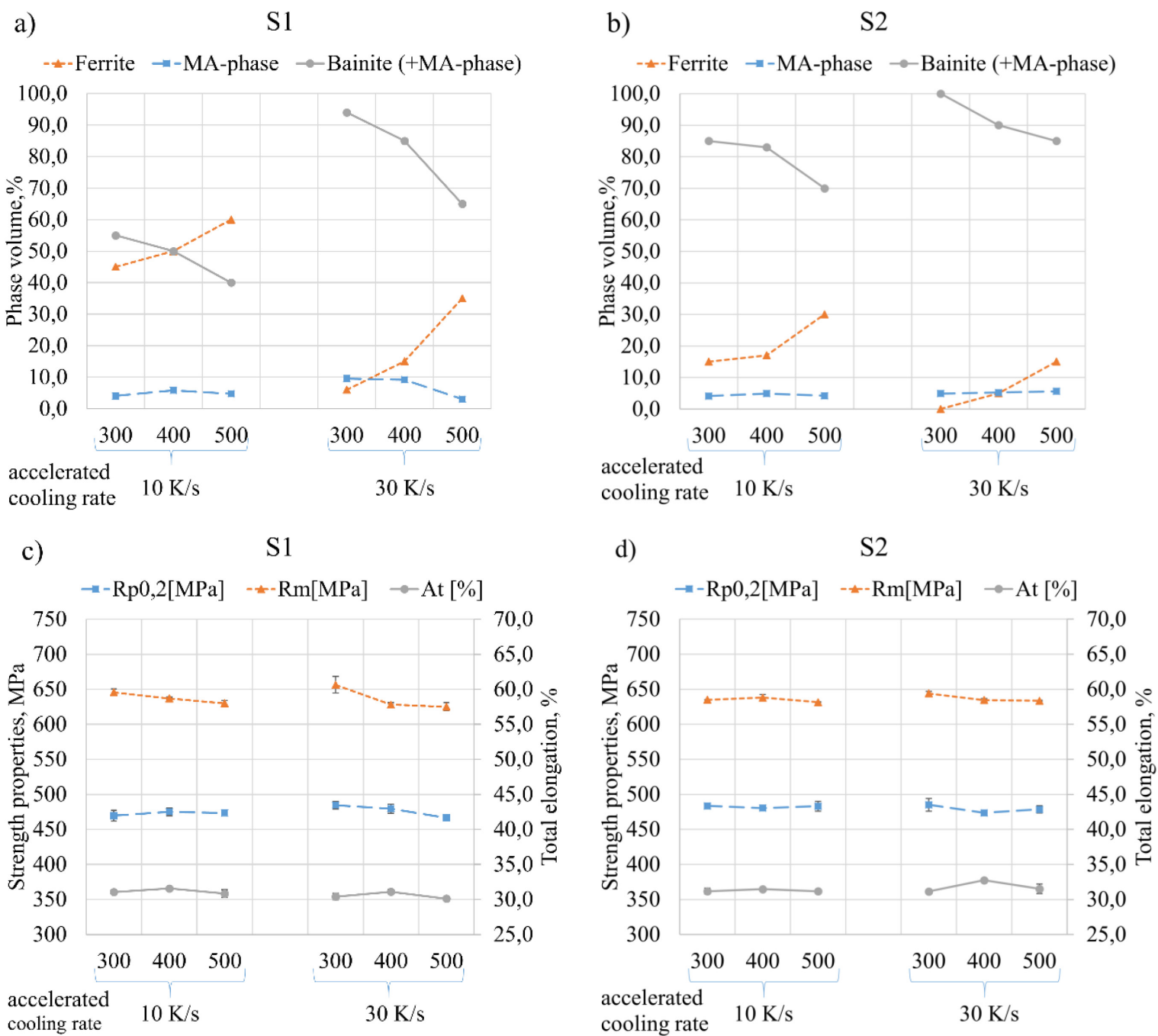

Fig. 3. Dependences of microstructure components $(a, b)$ and mechanical properties $(c, d)$ on the parameters of the accelerated cooling, where $R_{p 0,2}-$ yield strength; $R_{m}-$ ultimate strength; $A_{t}-$ total elongation ${ }^{1}$

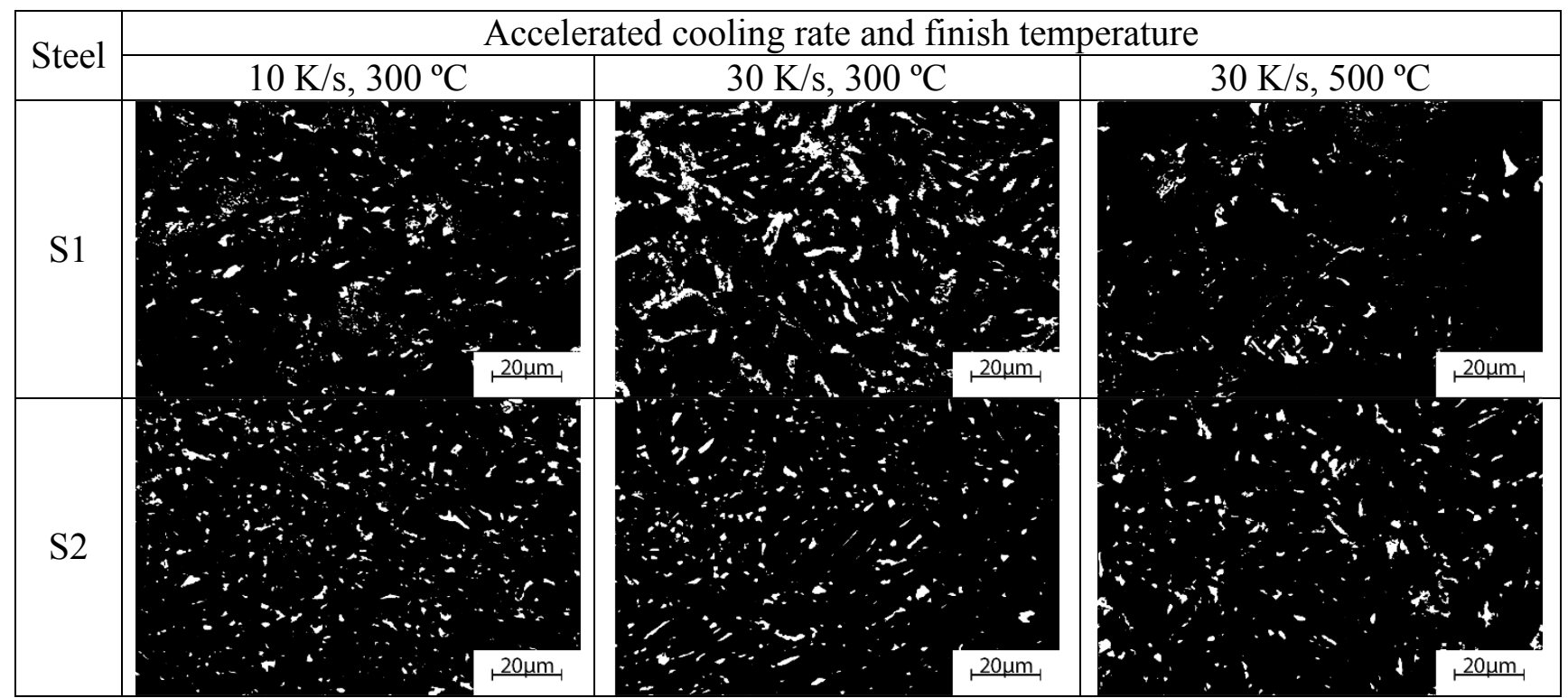

Fig. 4. Microstructure of MA phase with different parameters of the accelerated cooling rate and finish temperature

\footnotetext{
${ }^{1}$ The samples for the tensile test had shape and dimensions, which not include in standards. Therefore, the elongation can only be analyzed in the framework of this study.
} 
Influence of the holding time in the area of the bainite transformation on the microstructure and mechanical properties. In order to increase MA phase amount in the microstructure, it is necessary either to increase carbon diffusion rate from the formed bainite/ferrite to the untransformed austenite or to increase the time for more complete diffusion processes [12]. The last option can be carried out using isothermal holding in the bainite transformation area. It must lead to austenite stabilization due to increase of carbon concentration in the untransformed austenite. With the holding temperature increase, carbon diffusion rate also increases. However, based on the obtained data, shown in Fig. 5, the amount of MA phase initially increases holding, and later decreases due to formation of carbides in the microstructure. However, the holding time did not have significant effect either on quantity or MA phase size (Fig. 6).

The rest of the microstructure changed greatly under the influence of the isothermal holding. For example, temperature increase, the amount of ferrite increased and the average grain size also increased. With the holding time increase, the same effect was observed (Fig. 5). Despite microstructure changes, significant mechanical properties changes were not detected for the same reasons described in the previous chapter.

However, high temperatures and isothermal holding duration resulted in lower strength and elastic properties due to formation of carbides in the microstructure. As in the previous version of the technology, the first steel has a higher propensity to form carbides due to higher carbon content and a lower molybdenum content, which agrees with the results of [9].

a)

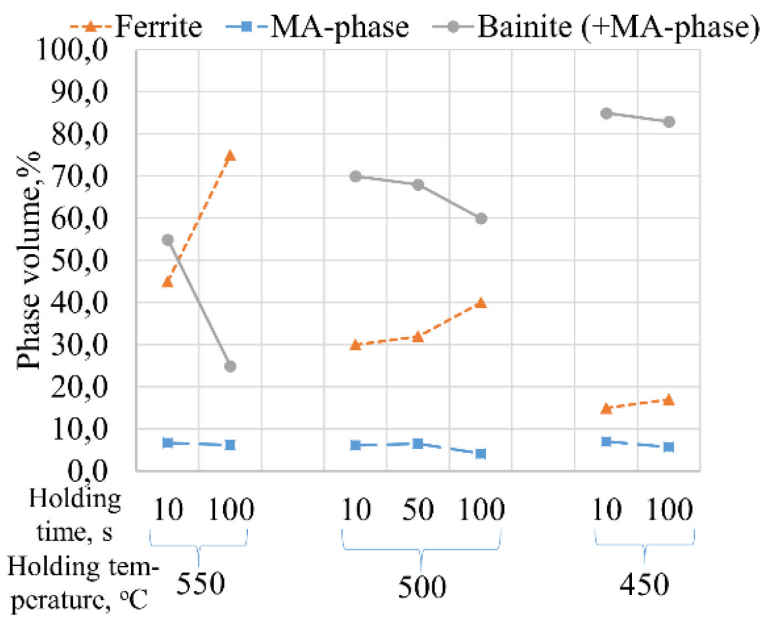

c)

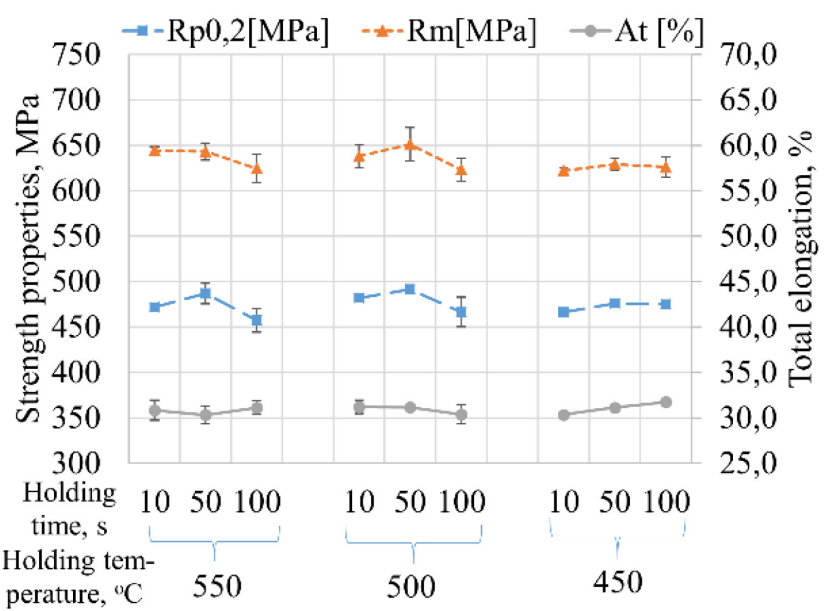

b)

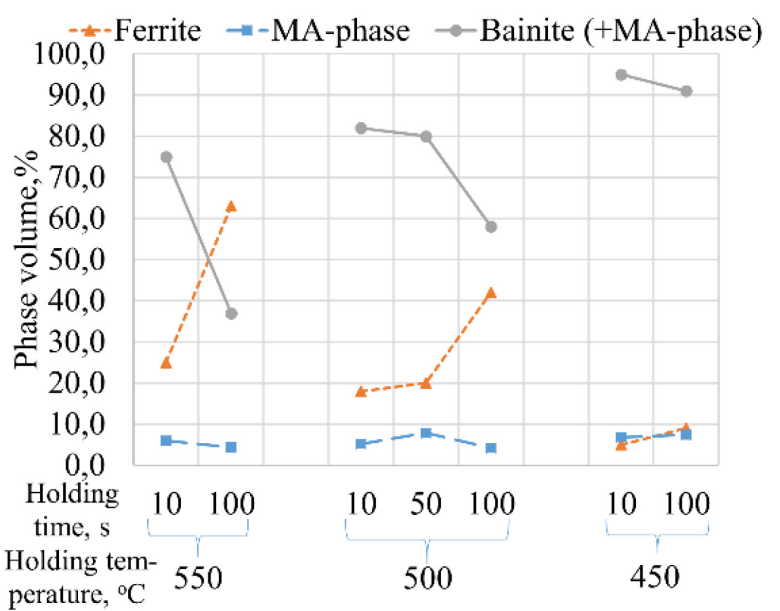

d)

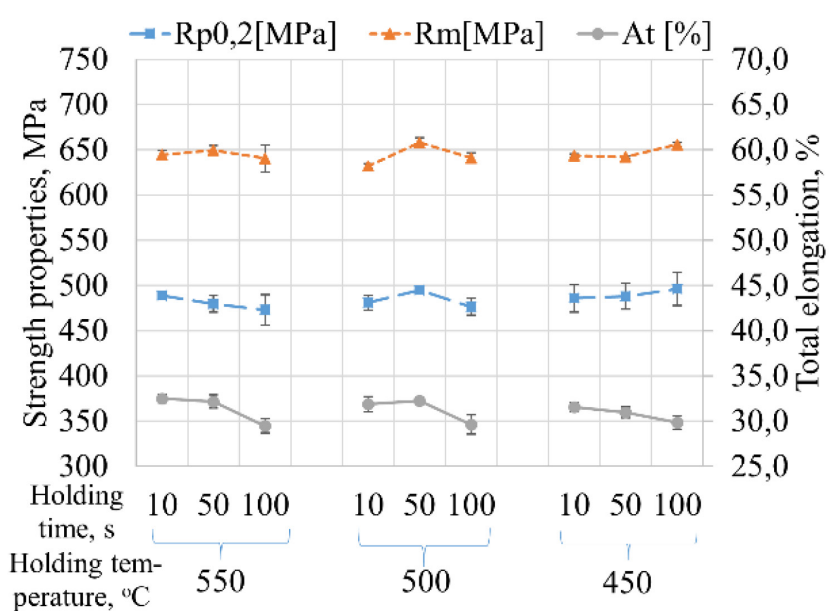

Fig. 5. Dependences of microstructure components $(a, b)$ and mechanical properties $(c, d)$ on the holding parameters, where $R_{p 0,2}-$ yield strength; $R_{m}$ - ultimate strength; $A_{t}$ - total elongation 


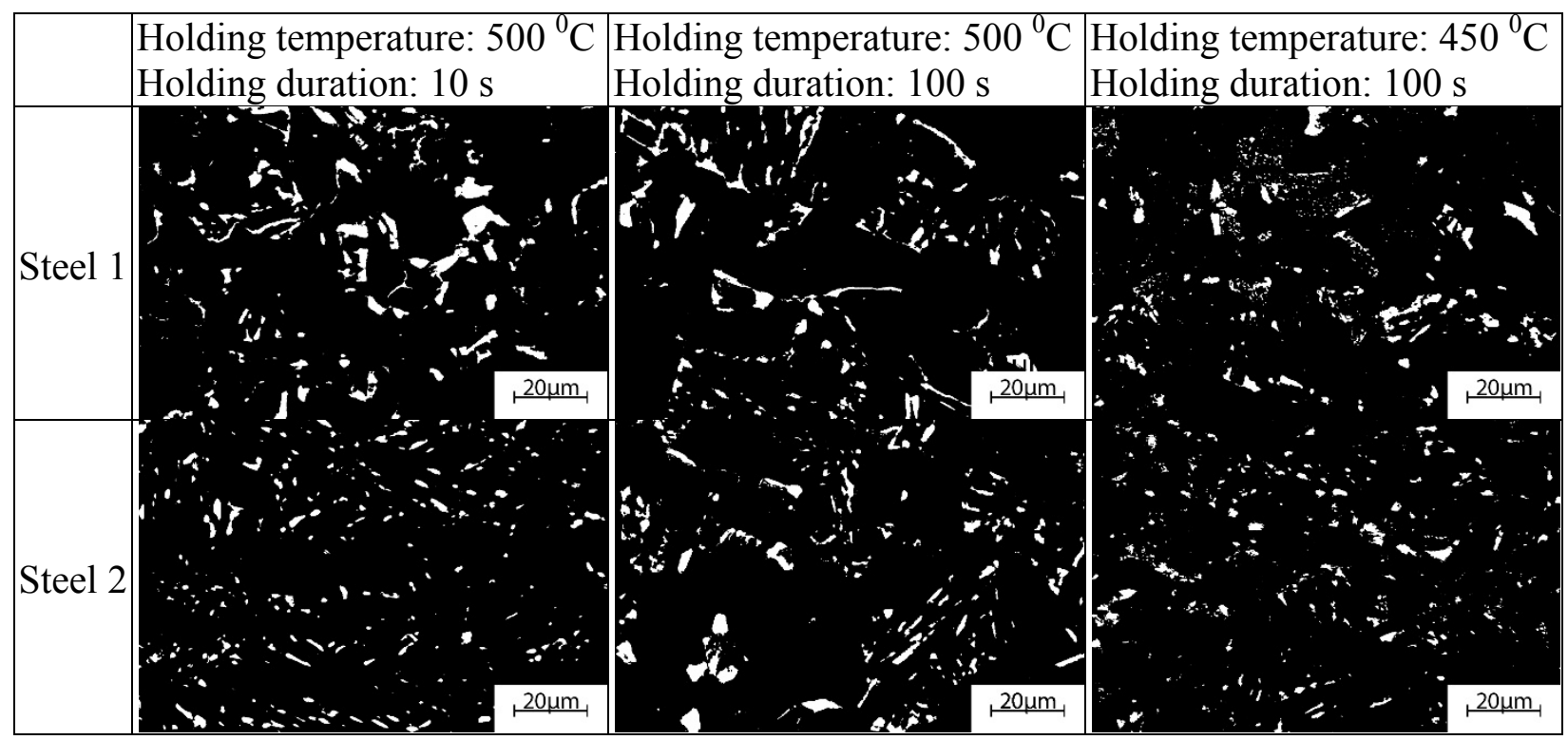

Fig. 6. Microstructure of the MA phase with different holding parameters

\section{Summary}

In this study, the effect of thermo-mechanical treatment with subsequent accelerated cooling and additional isothermal holding as well as the content of molybdenum and carbon on the formation of the two-microalloyed pipe steels microstructure, MA phase and mechanical properties was investigated. The present results can be summarized as follows:

1. Thermomechanical treatment with accelerated cooling permits to obtain steel with MA phase and a high bainite content in the microstructure;

2. Increase of the isothermal holding temperature and accelerated cooling finish temperature leads to increase of the ferrite content and average grain size;

3. Additional alloying with molybdenum reduces the average grain size, promotes the formation of the bainitic microstructure, and has a positive effect on the formation of MA phase;

4. The investigated steels have very stable level of mechanical properties under various parameters of accelerated cooling and additional isothermal holding. Therefore, holding is not very appropriate for these steels. However, it shows that plants can produce these steels without special additional equipment.

\section{Acknowledgements}

The authors also acknowledge the financial support of the European Social Fund for Germany and the Development Bank of Saxony.

\section{References}

[1] H.-G. Hillenbrand, A. Liessem, K. Biermann, C.J. Heckmann, V. Schwinn, Development of High Strength Material and Pipe Production Technology for Grade X120 Line Pipe, in: 2004 International Pipeline Conference, Volumes 1, 2, and 3, ASME, 2004, pp. 1743-1749.

[2] T. Shinmiya, N. Ishikawa, M. Okatsu, S. Endo, N. Shikanai, J. Kondo, others, Development of high deformability linepipe with resistance to strain-aged hardening by heat treatment on-line process, in: The Seventeenth International Offshore and Polar Engineering Conference, 2007.

[3] A. Kabanov, G. Korpala, R. Kawalla, S. Ionov, Effect of Hot Rolling and Thermal Treatment on the Microstructure Evolution of Microalloyed Bainitic Steels for Pipeline, KEM 746 (2017) $176-183$. 
[4] M. Okatsu, N. Shikanai, J. Kondo, Development of a High-Deformability Linepipe with Resistance to Strain-aged Hardening by HOP\textregistered(Heat-treatment On-line Process), JFE Technical Report 12 (2008) 8-13.

[5] C. Wang, X. Wu, J. Liu, N. Xu, Transmission electron microscopy of martensite/austenite islands in pipeline steel X70, Materials Science and Engineering: A 438 (2006) 267-271.

[6] H.K. Sung, D.H. Lee, S.Y. Shin, S. Lee, J.Y. Yoo, B. Hwang, Effect of finish cooling temperature on microstructure and mechanical properties of high-strength bainitic steels containing Cr, Mo, and B, Materials Science and Engineering: A 624 (2015) 14-22.

[7] L.-n. Duan, C. Yu, Q.-y. Liu, S.-j. Jia, C.-c. Jia, Microstructures and Mechanical Properties of X100 Pipeline Steel Strip, Journal of Iron and Steel Research, International 21 (2014) 227-232.

[8] H.F. Lan, L.X. Du, X.H. Liu, Microstructure and Mechanical Properties of a Low Carbon Bainitic Steel, steel research international 84 (2013) 352-361.

[9] J. Kong, C. Xie, Effect of molybdenum on continuous cooling bainite transformation of lowcarbon microalloyed steel, Materials \& design 27 (2006) 1169-1173.

[10] V. Biss, R.L. Cryderman, Martensite and retained austenite in hot-rolled, low-carbon bainitic steels, Metallurgical and Materials Transactions B 2 (1971) 2267-2276.

[11]S. Zajac, V. Schwinn, K.H. Tacke, Characterisation and quantification of complex bainitic microstructures in high and ultra-high strength linepipe steels, in: Materials Science Forum, 2005, pp. 387-394.

[12]H.K. Sung, S. Lee, S.Y. Shin, Effects of Start and Finish Cooling Temperatures on Microstructure and Mechanical Properties of Low-Carbon High-Strength and Low-Yield Ratio Bainitic Steels, Metallurgical and Materials Transactions A 45 (2014) 2004-2013. 